\title{
THREE DIMENSIONAL ANALYSIS OF BOLTED JOINT MEMBER STIFFNESS USING FRUSTA METHOD
}

\author{
Muhammad.M. Gogazeh and Hassan.A. AL Dabass \\ Mechanical Engineering Department, Faculty of Engineering \&Technology \\ Philadelphia University, Amman, Jordan
}

\begin{abstract}
Joint member stiffness has a great influence for both static and dynamic loading for a safe mechanical design of many types of bolted-jointed member connections. A three dimensional mathematical model for the jointed member system has been derived. This work provides a simple mathematical technique used to calculate different types a jointed member stiffness of a bolted connections. A finite element analysis is performed for the bolted joint and the model is used to predict stress field for a Grey Cast iron and aluminum alloy. Joint member stiffness is presented against member aspect ratio in dimensionless form. Results show good agreement as compared with those of used techniques of Montosh and Marschke
\end{abstract}

Keywords: Bolted Joint Member Stiffness.

Cite this Article: Muhammad.M. Gogazeh and Hassan.A. AL Dabass, Three dimensional analysis of bolted joint member stiffness using frusta method, International Journal of Mechanical Engineering and Technology 11(3), 2020, pp. 55-67. http://iaeme.com/Home/issue/IJMET?Volume=11\&Issue=3

\section{INTRODUCTION}

In this work the bolted joint member stiffness has been studied analytically, several concepts have been used to determine the extra components of stiffness (these steps will be discussed in the next section). However, these steps was originally established according to the approach and concepts of conical geometry was used by Shigley (Frusta) model $[1,2]$. There is another approach called Roster's pressure-cone model for stiffness calculations with a variable cone angle. This method is quite complicated so we here choose a simpler method with a fixed predetermined cone angle $\alpha[3,4]$.

\section{MATHEMATICAL FORMULATION}

\subsection{Basic Concepts}

The main concept of Frusta approach is that stress in the joints-member arrangements takes an approximate conical geometry shape (See Figure 1). This conical shape helps to derive the main governing equations based on circle and cone calculus . In general, stiffness is defined 
as $=\frac{P}{\partial}$; Where $\mathrm{P}$ is the compressive load raised from holding the joint to member. And $\delta$ is the deformation - deflection caused by this force. In this work the general form of stress distribution between the face and the head of the bolt is assumed to take conical form as shown in figure 1.

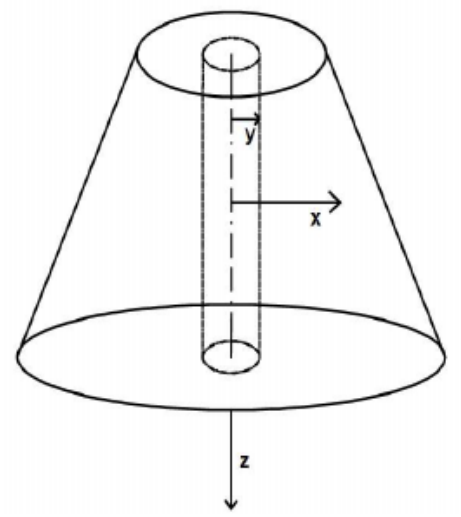

Figure 1 assumed conical stress distribution

\subsection{Derivation of the Governing Equations}

Here We will be use the basic equations corresponding circle, cone and their combination which called frusta, here is main equations:

The well-known general form of the circle equation is in two dimensions is:

$$
(x-a)^{2}+(y-b)^{2}=r^{2}
$$

The cone equation

$$
(x-a)^{2}+(y-b)^{2}=z^{2}
$$

These are the main two equations to be used to derive the main governing equations of bolt joint member stiffness. The fundamental equation used to determine the deformation $\delta$ is [1]:

$$
\delta=\frac{P}{E A}
$$

If we took a small deflection and a small displacement of a small element, equation [3] can be written as:

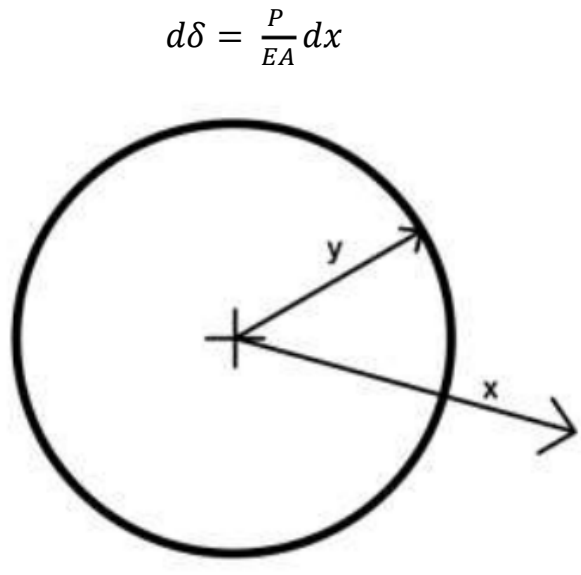

Figure 2 Circle conventions 
It is to be noted that the circle and cone equations can be represented as :

$$
\begin{aligned}
& x^{2}+y^{2}=r^{2} \\
& x^{2}+y^{2}=z^{2}
\end{aligned}
$$

First we will find the joint stiffness in $\mathrm{y}$ - direction which is denoted as $\mathrm{ky}$. For this purpose, we will use the circle equation (Eq. 5)

Solving this equation with respect to $\mathrm{x}$ to obtain

$$
x^{2}=r^{2}-y^{2}
$$

Taking the change of $\mathrm{x}$ with respect to $\mathrm{y}$ (i.e: we differentiate $\mathrm{x}$ with respect to $\mathrm{y}$ ), yields

$$
\begin{aligned}
& 2 x \cdot d x=-2 y \cdot d y \\
& \frac{d x}{d y}=-\frac{y}{x} \\
& d x=-\frac{y}{x} d y
\end{aligned}
$$

We could write the differential form of deformation equation (Eq. 4).

Substitute the value of $d x$ obtained above to have the $1^{\text {st }}$ order differential formula of deformation equation to be

$$
d \delta=-\frac{P}{E A} \frac{y}{x} d y
$$

Note that, $x$ here will be treated as a constant (horizontal distance along the width of the plates starting from centreline of the bolt). To find the value of the deformation $\delta$, we should do single integral to solve the $1^{\text {st }}$ order differential equation above.

For this purpose, we should define the following conventions first:

- The cone angle $\alpha$ : Whose value remains fixed from the definition of this approach. ( let $\alpha=30^{\circ}$ ).

- The plate thickness t: And it is used as the end limit the integral over z-axis, integral limits.

- The bolt radius $\mathrm{R}$ : is the nominal value of the bolt radius .

After we got the conventions cleared, we should solve Eq. 11 to find deformation, so we can relate it to stiffness by using Equation 3.

$$
\delta=\int_{0}^{R}-\frac{P}{E A} \frac{y}{x} d y
$$

Here the variable of integration is $y$. And we can make an additional presence of $y$ in the integration above by defining the term area [1]

$$
\begin{gathered}
A=\pi\left(r_{0}^{2}-r_{i}^{2}\right) \\
=\pi\left[\left(z \tan \alpha+\frac{x}{2}\right)^{2}-\left(\frac{y}{2}\right)^{2}\right]
\end{gathered}
$$

And by setting $\alpha=30^{\circ}$

$$
A=\pi\left[\left(0.5774 z+\frac{x}{2}\right)^{2}-\left(\frac{y}{2}\right)^{2}\right]
$$

So Eq. 12 becomes 


$$
\begin{aligned}
& \delta=-\frac{P}{E A} \int_{0}^{R} \frac{y}{x \pi\left[\left(0.5574 z \frac{x}{2}\right)^{2}-\left(\frac{y}{2}\right)^{2}\right]} d y \\
& \delta=-\frac{P}{E} \int_{0}^{R} \frac{y}{0.334 z^{2} x \pi+1.155 z x^{2} \pi+\frac{x^{3}}{4}-\frac{y^{2}}{4}}
\end{aligned}
$$

Using the basic concepts of calculus and integration, we can represent deformation equation as :

$$
\delta=\frac{P}{E} \frac{2}{x}\left[\ln \left(\frac{4 K-R^{2} x}{4 K}\right)\right]
$$

Where $\mathrm{K}$ is constant and it was set to simplify algebraic operations, and $K=0.334 z^{2} x \pi+$ $1.155 z x^{2} \pi+\frac{x^{3}}{4}$

Now we can find stiffness $\mathrm{k}$ from the general equation $k=\frac{P}{\delta}$ as

$$
k_{y}=\frac{E x}{2\left[\ln \left(\frac{4 k-R^{2} x}{4 k}\right)\right]}
$$

Now we find the stiffness in the direction of $\mathrm{z}\left(\mathrm{k}_{\mathrm{z}}\right)$ :

For this purpose, we will be using the cone equation (Eq. 6)

We solve this equation with respect to $\mathrm{x}$ so we obtain

$$
x^{2}=z^{2}-y^{2}
$$

As we exactly did with stiffness on $y$, we do same thing here with $\mathrm{z}$

$$
\begin{aligned}
& 2 x d x=2 z d z \\
& \frac{d x}{d z}=\frac{z}{x} \\
& d x=\frac{z}{x} d z
\end{aligned}
$$

Let us recall the differential form of deformation equation (Eq. 4) and substitute $\mathrm{dx}$ as found in Eq. 23 in Eq 4 to find

$$
d \delta=\frac{P}{E A} \frac{z}{x} d z
$$

As we did earlier, we can solve Eq. 24 as a separable differential equation as

$$
\delta=\int_{0}^{t} \frac{P}{E A} \frac{z}{x} d z
$$

Here, the variable of integration is $\mathrm{z}$ and it can be present in the integration by defining the term area as we last defined it

$$
A=\pi\left[\left(0.5774 z+\frac{x}{2}\right)^{2}-\left(\frac{y}{2}\right)^{2}\right]
$$

So Eq. 25 becomes

$$
\delta=\frac{P}{E} \int_{0}^{t} \frac{z}{0.334 z^{2} x \pi+1.555 z x^{2} \pi+\frac{x^{3}}{4}+\frac{y^{2}}{4}}
$$

The solution of the integral is

$$
\delta=\frac{P}{2 E}\left[0.334 x \pi+\frac{0.75}{z} x^{2} \pi \ln \left|0.334 z^{2} x \pi+1.555 z x^{2} \pi\right|\right]_{0}^{t}
$$

We can see that after substituting the limits of integration, it is an improper integration where we can find some values after substituting t minus infinite $\infty$ so the answer will be zero. 
Hence stiffness on this axis does not have a physical meaning. This is due to that this axis $(\mathrm{z})$ is containing a region that is not included between the two plates.

So we can only find stiffness $\mathrm{ky}$ with $\mathrm{x}$ and $\mathrm{z}$ as two dimensional values to be substituted in Eq. 19.

Now, we will use Eq. 19 to generate data curves to represent how stiffness varies with the position coordinates $\mathrm{x}$, and $\mathrm{z}$.

We will also show a simulation study trying to show how stress distributes in the members (plates) for some samples of materials.

\section{RESULTS AND DISCUSSION}

Now we will present a few resulted charts after applying Eq. 19 on some samples of geometries that are made of variety if materials. All the details will be shown separately for each sample. We will also include a simulation study.

\subsection{Case1: single plate analysis}

Grey Cast Iron plate, $10 \mathrm{~mm}$ hole diameter for bolt entrance at multiple fixed z coordinates as shown in Figure 4

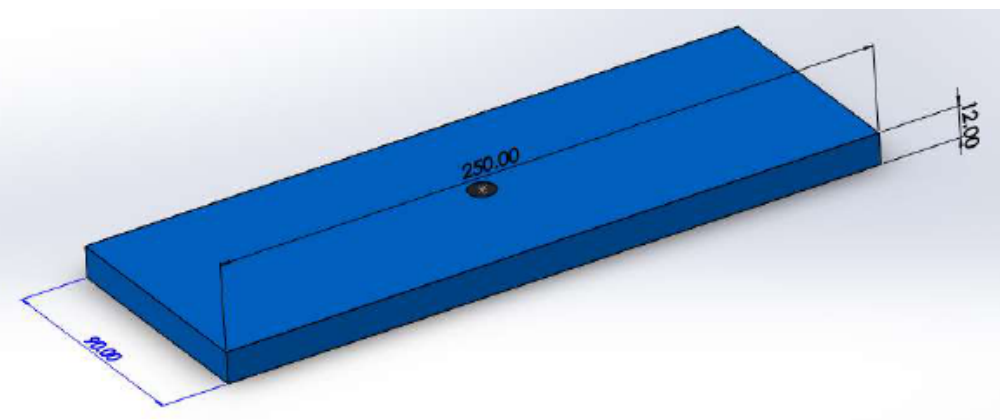

Figure 4 Geometric properties of the sample $(250 \times 12 \times 90)$

We will study the stiffness here for this sample as single. Using Eq. 19, we generated the following data curves:
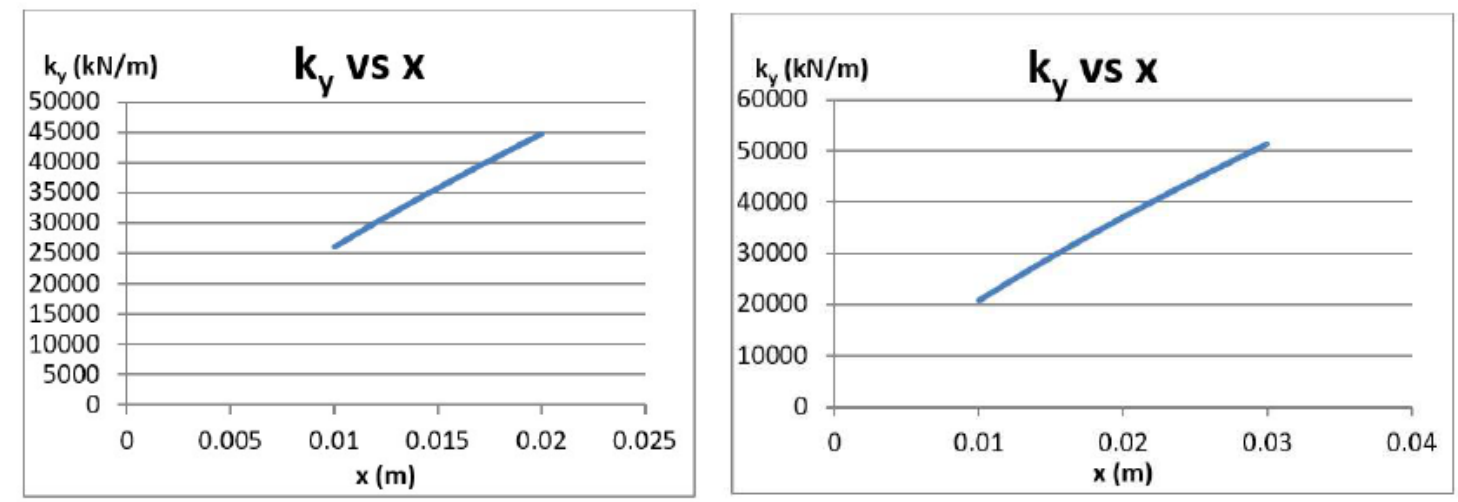
Muhammad.M. Gogazeh and Hassan.A. AL Dabass
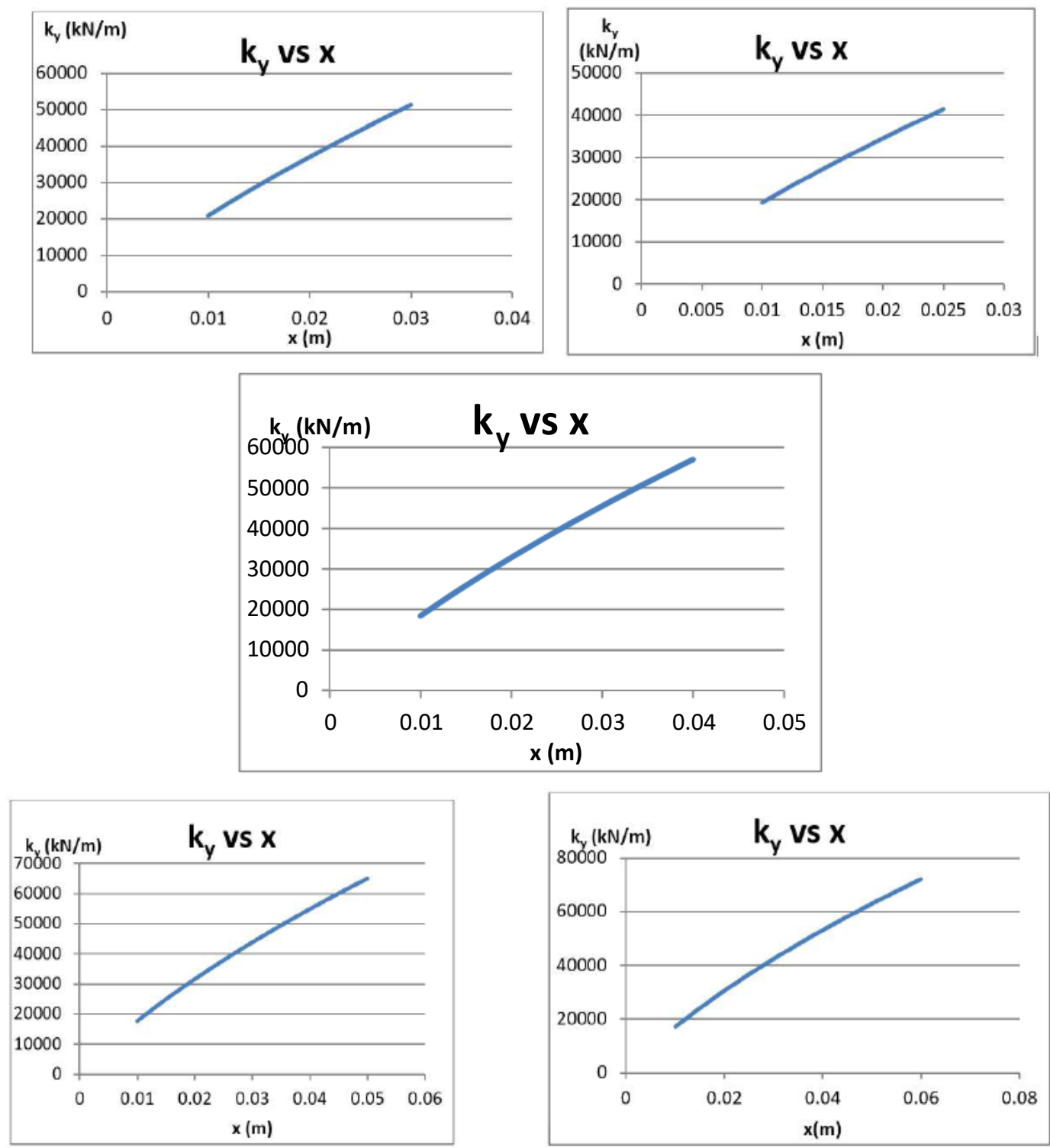

The shown graphs are for $\mathrm{z}=0 \mathrm{~cm}, 1 \mathrm{~cm}, 2 \mathrm{~cm}, 3 \mathrm{~cm}, 4 \mathrm{~cm}$, and $5 \mathrm{~cm}$, respectively for Grey Cast Iron sample. For better visualization, we may put these data curves into a single chart as

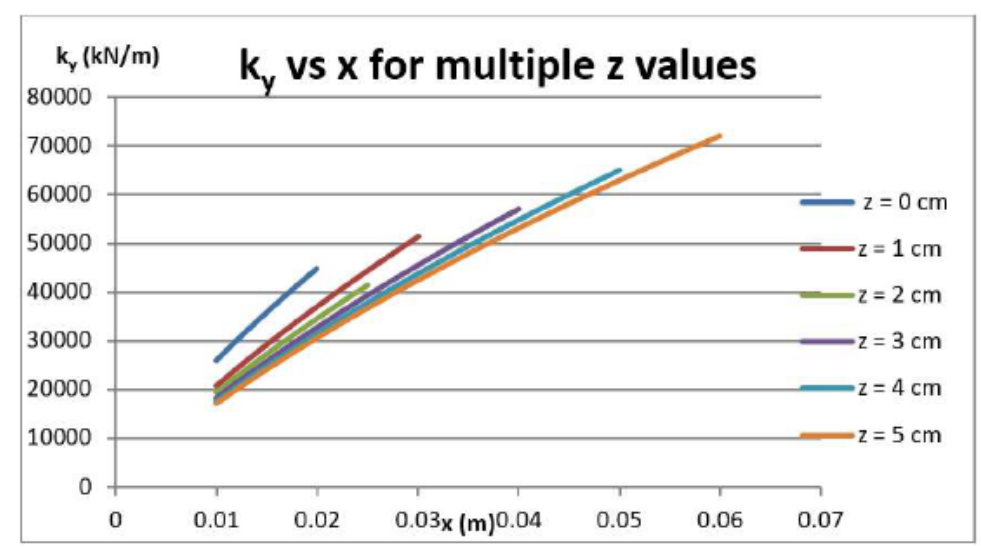

Figure 5 Combined results found on Figure a, b, c, d, e, and f for Grey Cast Iron sample 
We can see the relation is linear and the difference between each value of $\mathrm{z}$ is the interval of applying the calculations.

Now we will present a simulation study for the same sample but with applying a pre-load $\mathrm{P}$ of $70 \mathrm{~N}$ to see how stress distributes within the plate.

See Figure 6.

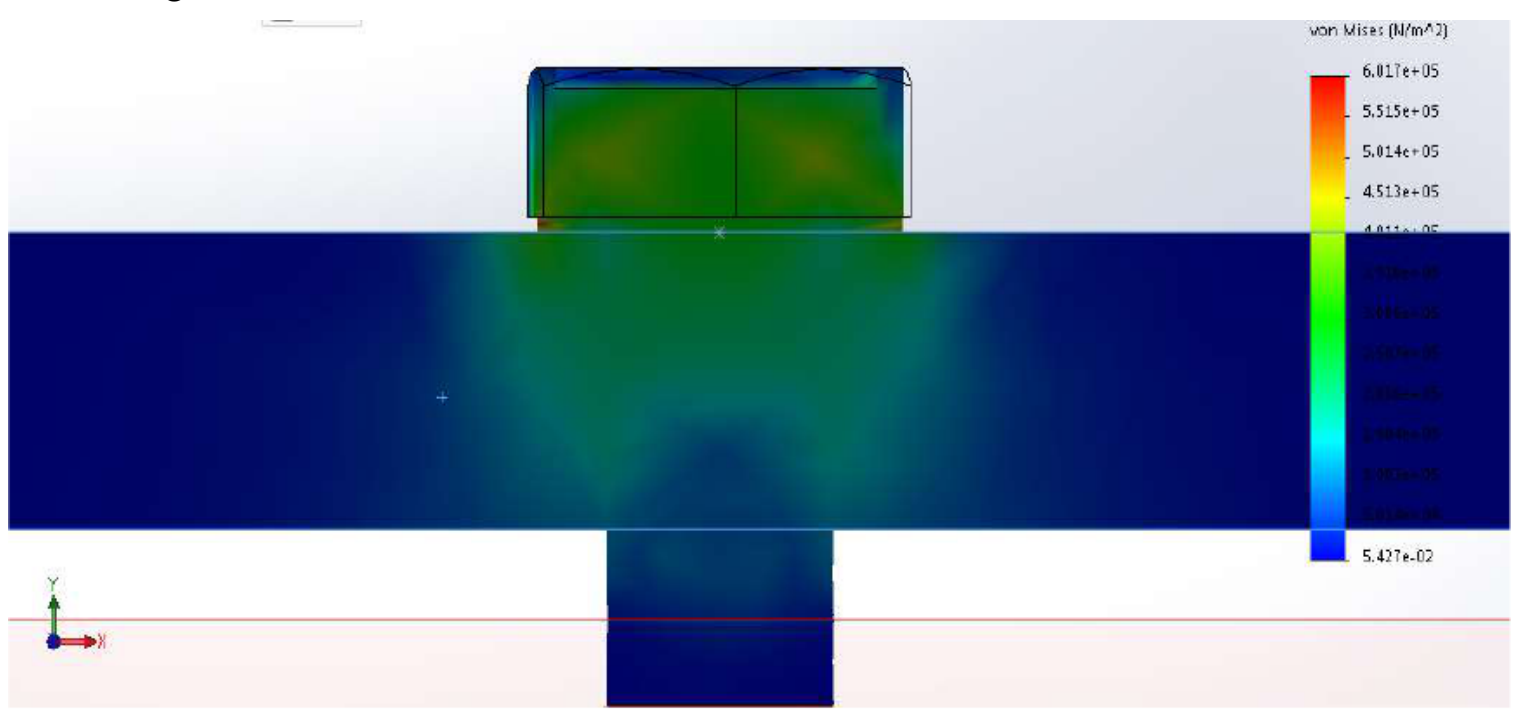

Figure 6 Stress distribution within the plate for Gray Cast Iron sample under the application of preload of $70 \mathrm{~N}$

It can be noted that how stress distributes in the shape of a conic, which this is the basic assumption on which the approach of Frustum by which stiffness equations are derived.

For a second case, Aluminium Alloy 1060-H12 plate, $10 \mathrm{~mm}$ hole diameter for bolt entrance at multiple fixed $\mathrm{z}$ coordinates is used in the presented analysis (see Figure 4).

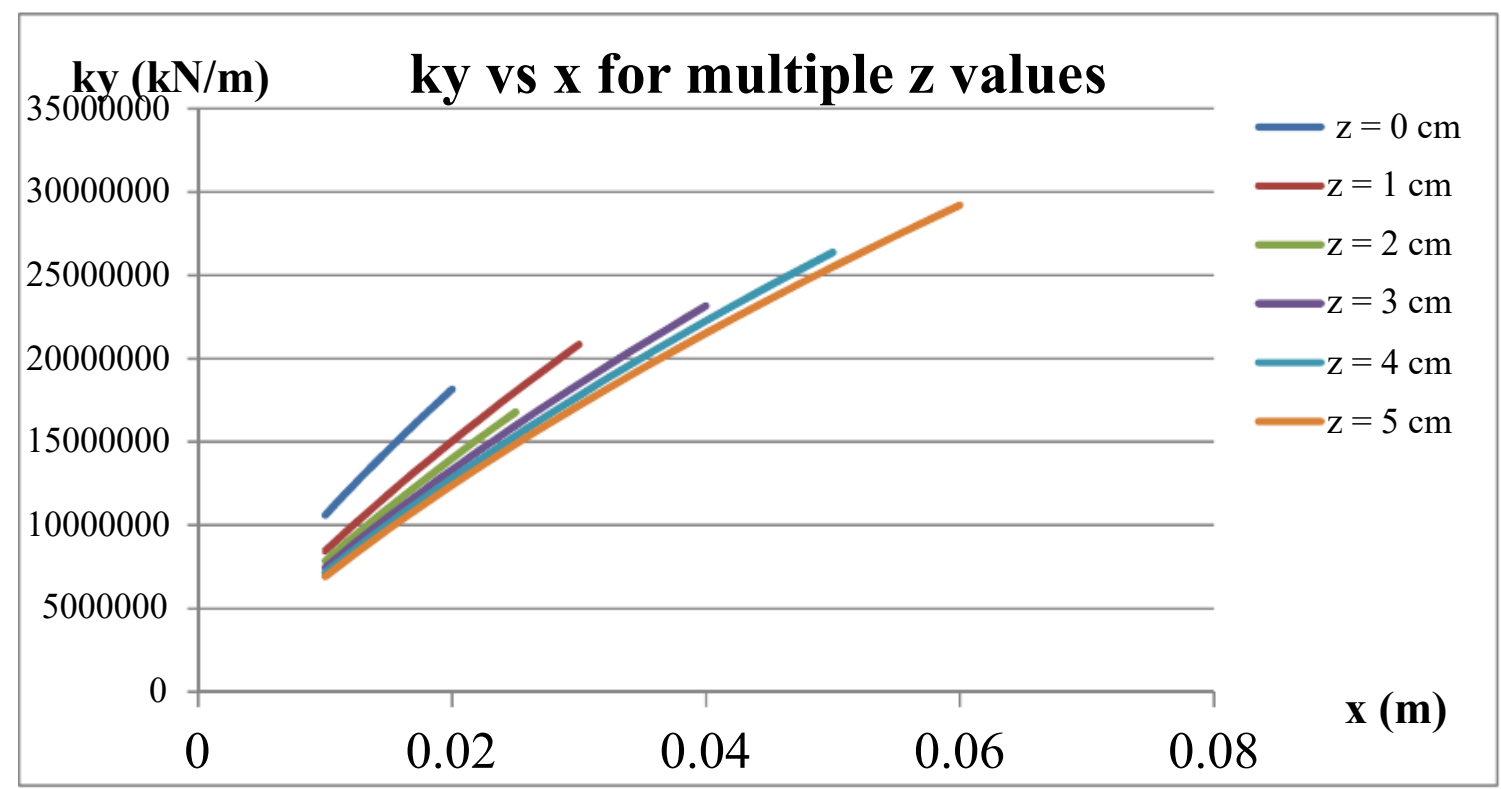

Figure 7 Stiffness VS. x for Aluminum Alloy 1060-H12 sample 
Now we will show how stress distribute within this sample plate for applying a pre-load $\mathrm{P}$ of 70 N. See Figure 8 . As seen from figure 8, the same behavior we obtained from the previous sample is still the same but with larger values.

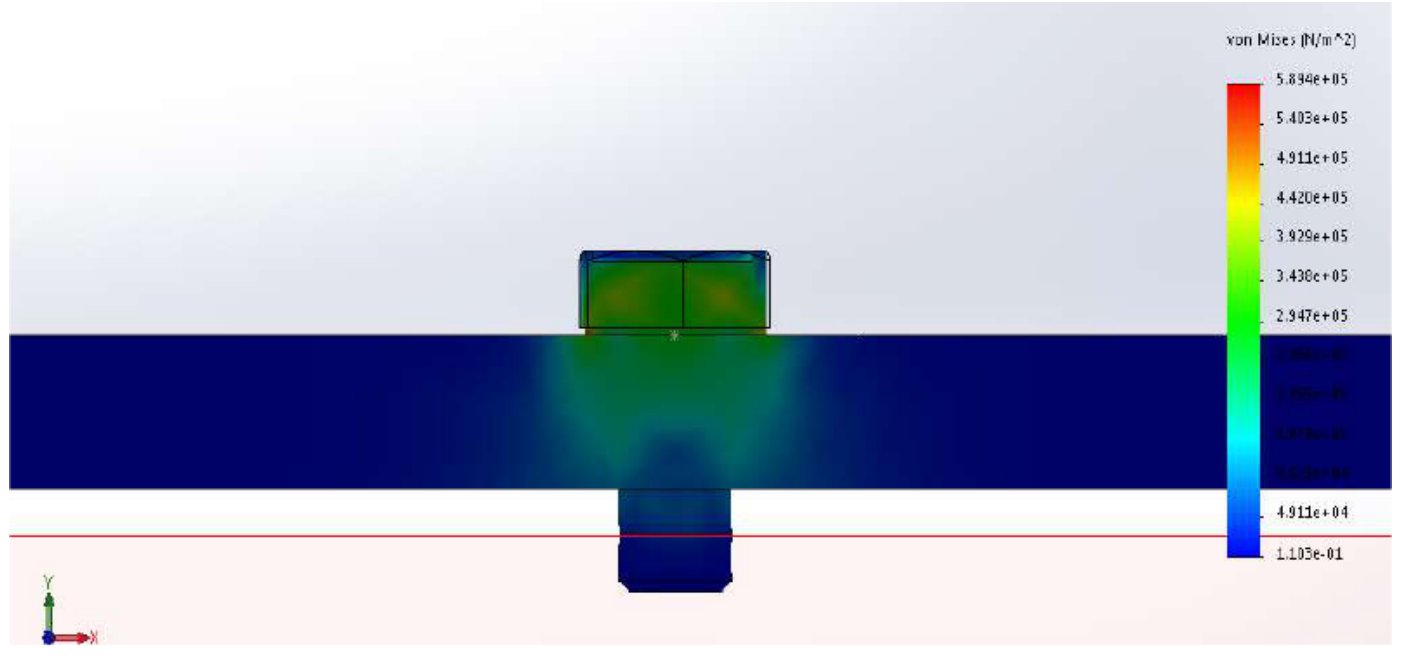

Figure 8 Stress distribution within the plate for Aluminum Alloy 1060-H12 sample under the application of pre-load of $70 \mathrm{~N}$

\subsection{Case2: Two joined cast iron plates analysis}

Now we may do the same simulation study but for two plates placed together and these plates will be given ductile and brittle one as follows:

- Brittle-Brittle joint (Grey Cast Iron-Grey Cast Iron)

- Ductile-Ductile joint (Aluminium Alloy 1060-H12- Aluminium Alloy 1060-H12)

- Brittle-Ductile joint (Grey Cast Iron- Aluminium Alloy 1060-H12)

Grey Cast Iron-Grey Cast Iron joint, $10 \mathrm{~mm}$ hole diameter for bolt entrance (see Figure 9). Each plate has the same dimensions as the one shown in Figure 4.

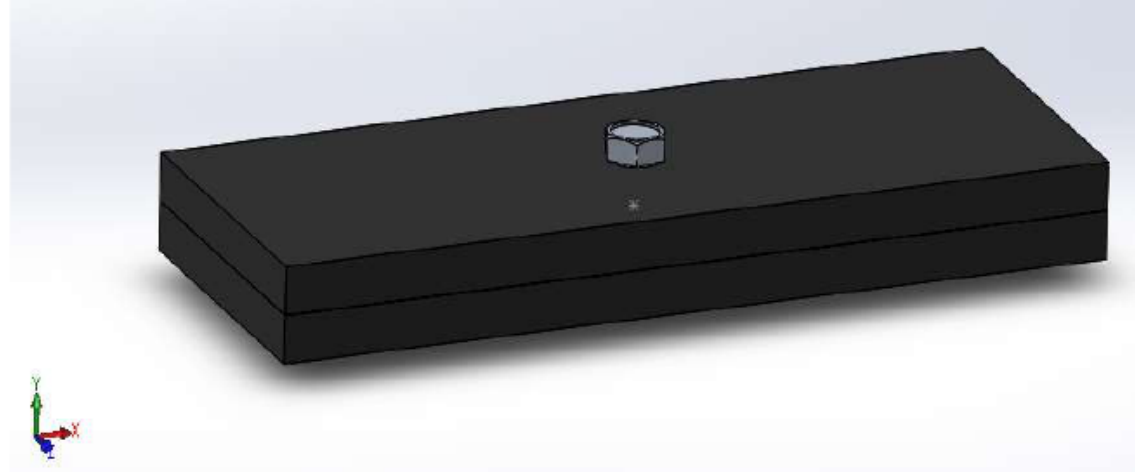

Figure 9 Grey Cast Iron-Grey Cast Iron joint, $10 \mathrm{~mm}$ hole diameter for bolt entrance

By applying a pre-load of $70 \mathrm{~N}$, we can find the stress distribution within these plates as shown in figure 10 


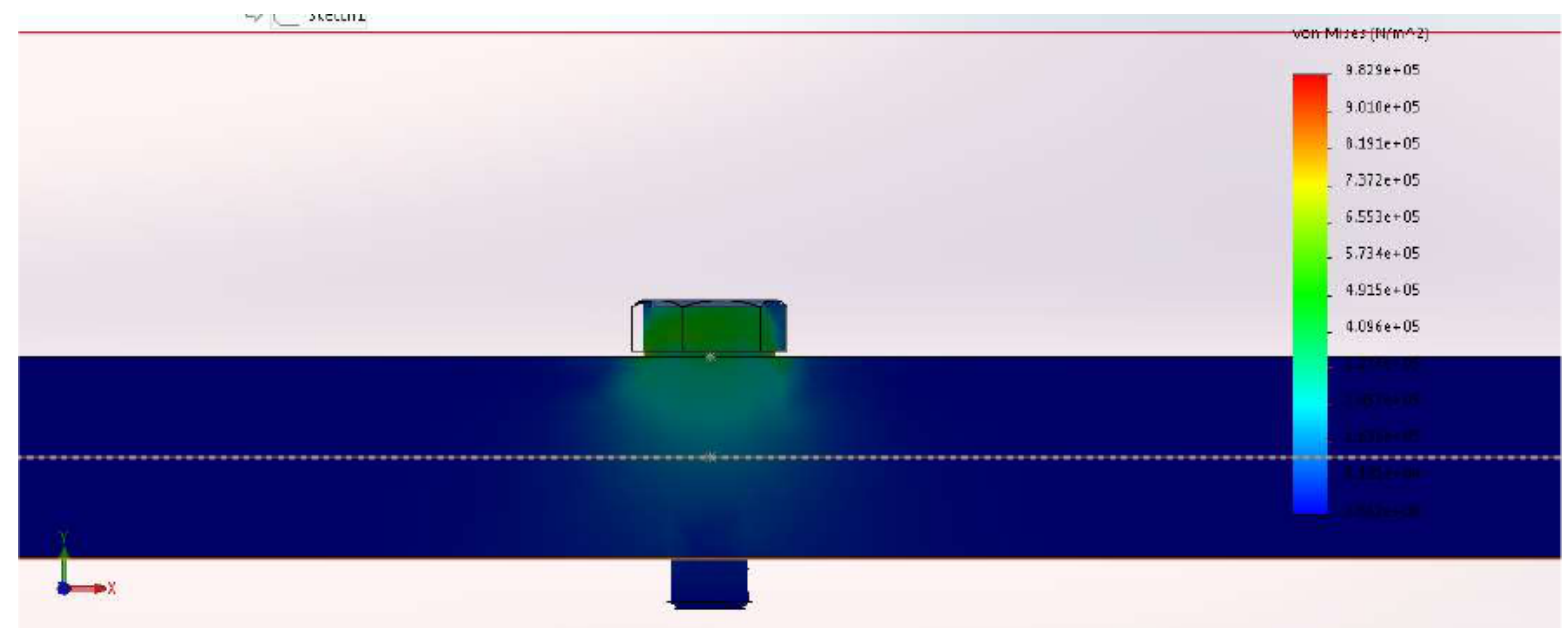

Figure 10 Stress distribution within Grey Cast Iron-Grey Cast Iron joint plates under the application of pre-load of $70 \mathrm{~N}$

\subsection{Case 3: Two joined Aluminium Alloy plates analysis}

In this case, Aluminium Alloy 1060-H12- Aluminium Alloy 1060-H12 joint, $10 \mathrm{~mm}$ hole diameter for bolt entrance as shown in Figure 11 is used for analysis purpose. Each plate has the same dimensions as ones shown in Figure 4.

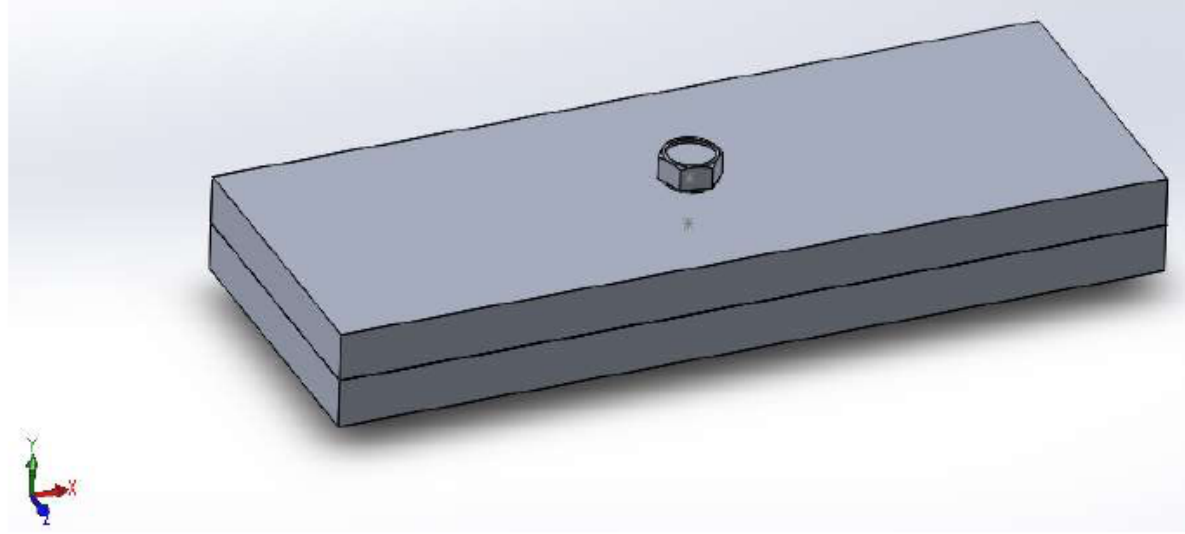

Figure 11Aluminium Alloy 1060-H12- Aluminium Alloy 1060-H12 joint, $10 \mathrm{~mm}$ hole diameter for bolt entrance

After applying a pre-load of $70 \mathrm{~N}$, the stress distribution within these plates is found as shown in Figure 12. 


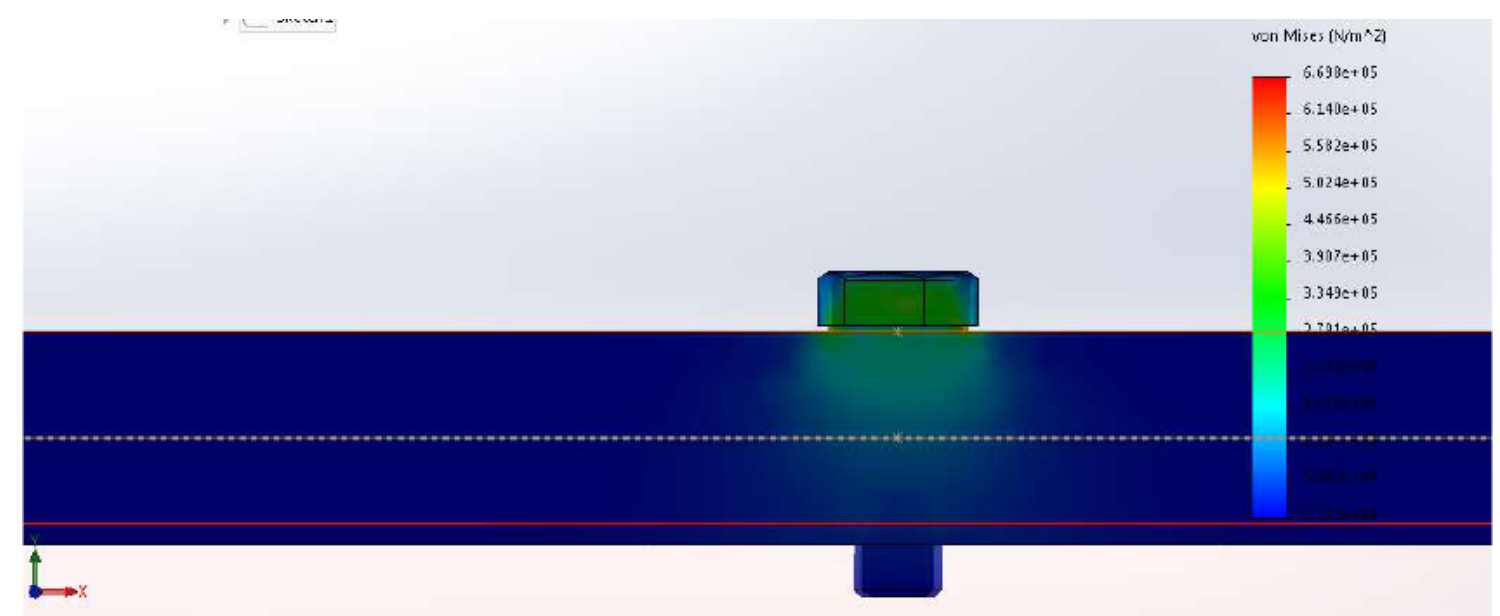

Figure 12 Stress distribution within Aluminium Alloy 1060-H12- Aluminium Alloy 1060-H12 joint plates under the application of pre-load of $70 \mathrm{~N}$

\subsection{Case 4: cast iron and aluminium joined plates}

In this case, a Grey Cast Iron and Aluminium Alloy 1060-H12 plates are joined by $10 \mathrm{~mm}$ hole diameter bolt as shown in see Figure 13. As the previous cases, the plates have the same dimensions as the one shown in Figure 4.

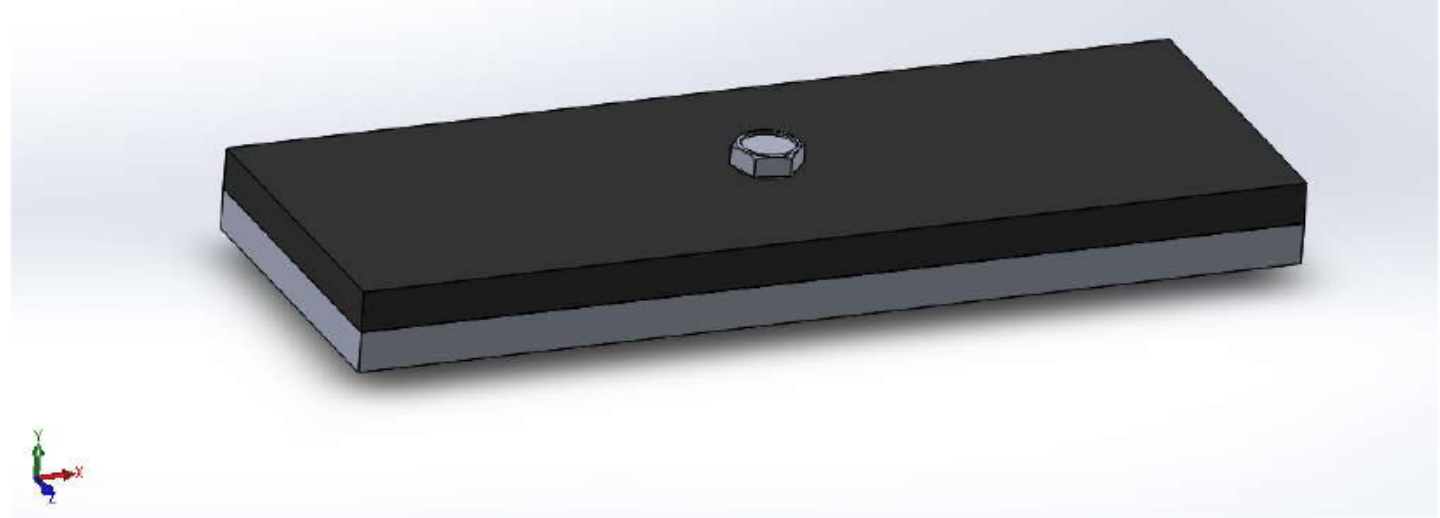

Figure 13 Grey Cast Iron- Aluminium Alloy 1060-H12 joint, $10 \mathrm{~mm}$ hole diameter for bolt entrance

When a pre-load of $70 \mathrm{~N}$ is applied to the problem, the stress distribution within these plates is found and shown in Figure 14. 


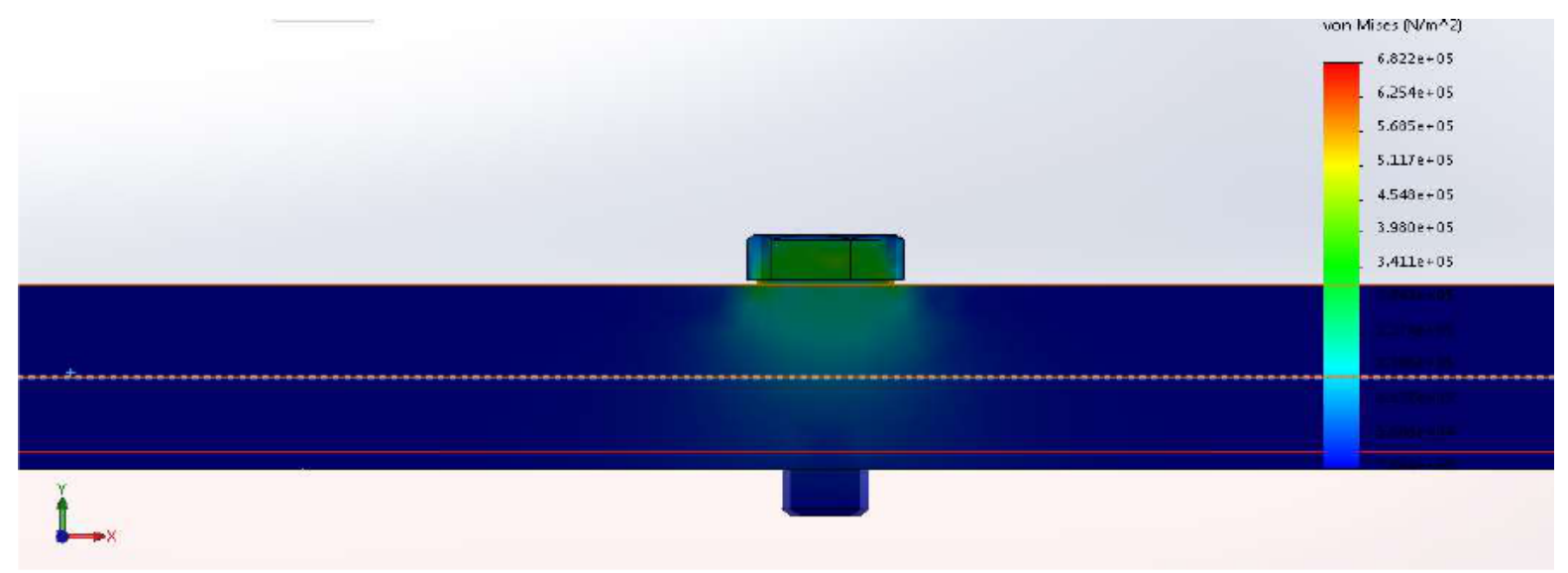

Figure 14 Grey Cast Iron- Aluminium Alloy 1060-H12 joint plates under the application of pre-load of 70

It should be noted that, these simulation studies were done using SolidWorks Simulation ${ }^{\circledR}$. The bolt is made of Aluminium Alloy 1060 and its standard were:

- For single plate, we used Formed hex screw, B18.2.3.2M - Formed hex screw, M10 x 1.5 x $20--20 \mathrm{WN}$

- For two-plated joint, we used B18.2.3.2M - Formed hex screw, M10 x 1.5 x 30 --30WN

\section{CONCLUSION}

It was shown how stiffness varies with distance along the width of the plate linearly. And this behaviour confirms the validity of using Hook's law to relate stiffness to deformation.

Using simulation solutions, it is shown how stress distributed within the member plate which in turn confirmed the validity of the frustum approach to predict stiffness.

These results were obtained under the assumption that the members' material is the same (i.e.: homogeneous ) having same modulus of elasticity $\mathrm{E}$.

Otherwise, these components can be applied for non-homogeneous members having number of $\mathrm{n}$ as several springs in series:

$$
\frac{1}{k_{m}}=\frac{1}{k 1}+\frac{1}{k 2}+\frac{1}{k 3}+\cdots+\frac{1}{k_{n}}
$$

\section{REFERENCE}

[1] Guang Zhao, Zhilang Xiong, Xin Jin , Loong Hou and Wendong Gao, Prediction of contact stiffness in bolted interface with natural frequency experiment and finite element analysis ,J.Tribology International, Vol .127, Nov.2018 .PP.157-164.

[2] Z.X. Wang, Y.Q.Wang, G.X.Zhang, Y.J.Shi, test and parametric analysis of aluminium alloy bolted joints of different material types. J. Construction and building materials , Vol .185, 2018 PP589-599.

[3] R.M.Hizam , Allan .C.Manalo, Warna Karunasena,Yu Bui ,effect of bolt threads on the double lap joint strength of pultruded fibre reinforced polymer composite material, J. Construction and Building Materials, Vol 181, 2018 ,PP185-198.

[4] T. Yang, S.H. Fan, C.S. Lin, Joint stiffness identification using FRF measurements Comput Struct, 81 (2003), pp. 2549-2556 
[5] Y. Song, C.J. Hartwigsen, D.M. McFarland, et al.Simulation of dynamics of beam structures with bolted joints using adjusted Iwan beam elements J Sound Vib, 273 (2004), pp. 249-276

[6] E.F. Crawley, A.C. Aubert . Identification of nonlinear structural elements by forcestate mapping Am Inst Aeronaut Astronaut J, 24 (1986), pp. 155-162

[7] H. Ouyang, M.J. Oldfield, J.E. Mottershead . Experimental and theoretical studies of a bolted joint excited by a torsional dynamic load Int J Mech Sci, 48 (2006), pp. 14471455

[8] H. Ahmadian, H. Jalali .Generic element formulation for modelling bolted joints Mech Syst Signal Process, 21 (5) (2007), pp. 2318-2334

[9] J. Cunha, E. Foltête, N. Bouhaddi, Evaluation of stiffness of semi-rigid joints in pultruded profiles from dynamic and static data by using model updating technique Eng Struct, 30 (4) (2008), pp. 1024-1036

[10] Wang, P. Sas . A method for identifying parameters of mechanical joints, American society of mechanical engineers J Appl Mech, 57 (1990), pp. 337-342

[11] Y. Ren, T.M. Lim, M.K. Lim . Identification of properties of nonlinear joints using dynamic test dataJ Vib Acoust, 120 (1998), pp. 324-330

[12] F. Huda, I. Kajiwara, N. Hosoya, S. Kawamura . Bolt loosening analysis and diagnosis by non-contact laser excitation vibration tests Mech Syst Signal Process, 40 (2013), pp. 589604

[13] I. Kajiwara, D. Miyamoto, et al. . Loose bolt detection by high frequency vibration measurement with non-contact laser excitation J Syst Des Dynam, 5 (8) (2011), pp. $1559-1571$

\section{NOMENCLATURE}

k: bolt Stiffness $(\mathrm{N} / \mathrm{m})$

$\mathrm{k}_{\mathrm{y}}$ : Stiffness on $\mathrm{y}-$ direction $(\mathrm{N} / \mathrm{m})$

$\mathrm{k}_{\mathrm{z}}$ : Stiffness on $\mathrm{z}$ - direction $(\mathrm{N} / \mathrm{m})$

$\mathrm{x}: 1^{\text {st }}$ Circle and conic coordinate

$\mathrm{y}: 2^{\text {nd }}$ Circle and conic coordinate

P: Pre-load force $(\mathrm{N})$

$\delta$ : Deflection or deformation $(\mathrm{m})$

a: Circle canter $1^{\text {st }}$ coordinate

b: Circle canter $2^{\text {nd }}$ coordinate

A: Conical shape area $\left(\mathrm{m}^{2}\right)$

$\mathrm{E}$ : Young modulus of elasticity ( $\mathrm{MPa})$

$r$ : Radius of the circle used in conical model

$\mathrm{r}_{\mathrm{o}}$ : Outside radius of the hole $(\mathrm{m})$

$\mathrm{r}_{\mathrm{i}}$ : Inside radius of the hole $(\mathrm{m})$

$\mathrm{z}$ : Elevation of the conic model

$\mathrm{K}$ : Constant to simplify integration 


\section{LIST OF FIGURES}

\begin{tabular}{|c|c|}
\hline No. & Figure Caption \\
\hline 1 & The assumed conical distribution of stress \\
\hline 2 & Circle conventions \\
\hline 3 & Deflection Conventions and definitions \\
\hline 4 & Geometric properties of the sample $(250 \mathrm{x} 12 \times 90) \mathrm{mm}$ \\
\hline 5 & Combined results found on Figure a, b, c, d, e, and f for Grey Cast Iron sample \\
\hline 6 & $\begin{array}{c}\text { Stress distribution within the plate for Gray Cast Iron sample under the application of pre-load } \\
\text { of 70 N }\end{array}$ \\
\hline 7 & Stiffness VS - x dimension for Aluminum Alloy 1060-H12 sample \\
\hline 8 & $\begin{array}{c}\text { Stress distribution within the plate for Aluminum Alloy 1060-H12 sample under the application } \\
\text { of pre-load } 70 \mathrm{~N}\end{array}$ \\
\hline 9 & Grey Cast Iron-Grey Cast Iron joint, 10 mm hole diameter for bolt entrance \\
\hline 10 & Stress distribution within Grey Cast Iron joint plates under the application of pre-load of 70 N \\
\hline 11 & $\begin{array}{c}\text { Aluminium Alloy 1060-H12- Aluminium Alloy 1060-H12 joint, 10 mm hole diameter for bolt } \\
\text { entrance }\end{array}$ \\
\hline 12 & $\begin{array}{c}\text { Stress distribution within Aluminium Alloy 1060-H12- Aluminium Alloy 1060-H12 joint plates } \\
\text { under the application of pre-load of 70 N }\end{array}$ \\
\hline 13 & Grey Cast Iron- Aluminium Alloy 1060-H12 joint, 10 mm hole diameter for bolt entrance \\
\hline 14 & $\begin{array}{c}\text { Grey Cast Iron- Aluminium Alloy 1060-H12 joint plates under the application of pre-load of } \\
70 \mathrm{~N} \text {. }\end{array}$ \\
\hline
\end{tabular}

